\title{
A Role for Extracellular Amastigotes in the Immunopathology of Chagas Disease
}

\author{
Julio Scharfstein ${ }^{+}$, Alexandre Morrot \\ Laboratório de Imunologia Molecular, Instituto de Biofisica Carlos Chagas Filho, Universidade Federal do \\ Rio de Janeiro, 21944-970 Rio de Janeiro, RJ, Brasil
}

In spite of the knowledge obtained about immune control of Trypanosoma cruzi (T. cruzi) infection, the mechanisms responsible for the variable clinico-pathological expression of Chagas disease remain unknown. In a twist from previous concepts, recent studies indicated that tissue parasitism is a prerequisite for the development of chronic myocarditis. This fundamental concept, together with the realization that T. cruzi organisms consist of genetically heterogeneous clones, offers a new framework for studies of molecular pathogenesis. In the present article, we will discuss in general terms the possible implications of genetic variability of $\mathrm{T}$. cruzi antigens and proteases to immunopathology. Peptide epitopes from a highly polymorphic subfamily of trans-sialidase (TS) antigens were recently identified as targets of killer T cell (CTL) responses, both in mice and humans. While some class I MHC restricted CTL recognize epitopes derived from amastigote-specific TS-related antigens (TSRA), others are targeted to peptide epitopes originating from trypomastigote-specific TSRA. A mechanistic hypothesis is proposed to explain how the functional activity and specificity of class I MHC restricted killer T cells may control the extent to which tissues are exposed to prematurely released amastigotes. Chronic immunopathology may be exacerbated due the progressive accumulation of amastigote-derived antigens and pro-inflammatory molecules (eg. GPI-mucins and kinin-releasing proteases) in dead macrophage bodies.

Key words: cysteine proteinases - cruzipain - kinins - amastigotes - Trypanosoma cruzi - Chagas disease

\section{DYNAMICS OF IMMUNE RESPONSE EARLY IN T. CRUZI INFECTION}

Host resistance to microbial infection integrates two major and overlapping defense systems, innate and adaptive immunity. Intracellular pathogens can quickly relay activation signals that stimulate non-specific humoral and cellular effector responses in the infected host. Assisted by these innate defense responses, the rate of microbial growth is delayed for several days, while the adaptive branch of immunity gets prepared to confront the pathogen on the long term. The infection can only persist when the organisms succeed to counteract the selective pressure imparted by immune effector cells and/or antibodies. In the case of chronic viral infections, immune subversion is often targeted against intracellular pathways involved in antigen processing and/or presentation by class I MHC molecules.

Supported by FUJB, Faperj and Pronex II.

${ }^{+}$Corresponding author. Fax: +55-21-280.8193. E-mail: scharf@biof.ufrj.br

Received 9 June 1999

Accepted 9 August 1999
In the case of T. cruzi, the mechanisms which enable their persistent growth in mammalian tissues were not characterized. As discussed later in this text, there are reasons to think that the molecular diversity of $T$. cruzi organisms may affect the dynamics of tissue and organ involvement. This is supported by recent evidences showing that acute infection with parasite stocks pertaining to different genotypic groups induce distinct histopathology patterns in acutely infected mice (de Diego et al. 1998) Recently confirmed by research in genetic epidemiology (Souto et al. 1996, Brisse et al. 1998), the concept that $T$. cruzi has a multiclonal descent was earlier proposed on the basis of isoenzyme (Miles et al. 1978, Romanha et al. 1979, Ready et al. 1980, Tibayrenc et al. 1986) and fingerprint analysis of k-DNA (Morel et al. 1980). While not excluding the importance of host genetics as a determinant of host susceptibility in vivo (Trischman et al. 1978), studies performed with laboratory strains of T. cruzi (Brener 1965, Andrade \& Andrade 1966, Mello \& Brener 1978) and also with parasite clones (Postan et al. 1983, de Diego et al. 1998, Macedo \& Pena, 1998) suggested that the variable expression of Chagas disease may be influenced, at least to some extent, by the genetic and biological diversity of the T. cruzi clones which circulate in sylvatic and domestic reservoirs. 
In spite of the poor knowledge about the innate responses which metacyclic trypomastigotes stimulate in wound mucosal tissues, this defense system should be fully operative by the time the first cycles of intracellular infection are completed. Once released from disrupted cells, the trypomastigotes spread the infection via the bloodstream and/or lymphatics. At this early stage of infection, a wide range of non-phagocytic host cells can be invaded by the trypomastigotes, but host cell target preference can differ markedly from one parasite clone to another due to the variable composition and expression levels of their cell surface adhesion molecules, some of which are highly polymorphic (Affranchino et al. 1989, Tackle \& Cross 1991, Colli 1993, Schenckman et al. 1994, Giordanno et al. 1994, Pereira et al. 1996, Salazar et al. 1996) or due to differential signaling ability of the invading parasite clones (Ming et al. 1995, Burleigh \& Andrews 1998).

The survival strategies of the sub-populations of $T$. cruzi clones which preferentially invade mononuclear phagocytic cells (reticulotropic parasites) are not sufficiently well characterized. These parasite sub-populations must either inhibit macrophage activation or somehow protect themselves from their microbicidal machinary in order to survive in genetically resistent host. As true for other intracellular pathogens, innate immunity against $T$. cruzi depends on the release of $\gamma$-IFN by NK cells (Aliberti et al. 1996, Cardillo et al. 1996). In genetically resistant strains, the onset of this $\mathrm{T}$ cell independent pathway depends on IL-12 production by activated macrophages and appears to be stimulated by tGPI-mucins, a potent class of proinflammatory molecules expressed by trypomastigotes and by amastigotes (Camargo et al. 1997). Synergized by TNF- $\alpha$ (Munoz-Fernandez et al. 1992), $\gamma$-IFN induces a heightened state of microbicidal activation of macrophages in genetically resistant animals, at least so during the first days of infection. The mechanisms by which activated macrophages ultimately exert their anti-parasite activity is somewhat controversial, but there are indications the production of nitric oxide (NO) metabolites is critically involved (Gazzinelli et al. 1992). As for the innately susceptible inbred mice strains, their response to infection is dominated by the macrophage down-regulatory cytokines IL-10 or TGF- $\beta$ (Silva et al. 1992, Gazzinelli et al. 1992). Interestingly, recent evidences suggest that factors leading to the accumulation of cyclic AMP by macrophages may down-regulate the pro-inflammatory response which tGPI-mucins otherwise stimulate in such cells (Procopio et al. 1999); under these conditions, tGPI-mucins can upregulate IL-10 expression by macrophages, thereby inhib- iting the synthesis of both IL-12(p40) and TNF$\alpha$. In short, parasite factors which induce the accumulation of c-AMP may convert a potentially resistant macrophage into a highly susceptible target cell.

In contrast to parasite clones that preferentially invade macrophages, the sub-populations that invade non-phagocytic cells in the first days of infection will grow undisturbed because CTL effectors are not as yet prepared to act. The necrosis caused by host cell death is extensive and may involve multiple tissues and organs (Lenzi et al. 1996, Cotta de Almeida et al. 1977). Inflamed tissues are exposed to high amounts of parasite antigens, either released by extracellular parasites or leaked from killed organisms. Once captured by immature dendritic cells, these antigens are transported to the proximal draining lymph nodes. After upregulating their $\mathrm{MHC}$ molecules, the matured dendritic cells present the MHC-bound peptide antigens to naive $\mathrm{CD} 4^{+}$and $\mathrm{CD} 8^{+} \mathrm{T}$ cells. Depending on the genetic background of the individual, on the antigen load and on the cytokine balance, the functional characteristics of $\mathrm{CD} 4^{+} \mathrm{T}$ cells primed by dendritic cells can be rapidly polarized under the influence of type 1 or type 2 stimulating cytokines (IL-12 and IL-4, respectively). Driven by inflammatory chemokines, these circulating $\mathrm{CD}^{+} \mathrm{Th} 1$ and $\mathrm{CD} 8^{+} \mathrm{T}(\mathrm{Tc} 1)$ attach to the vascular adhesins expressed by activated endothelial cells (Kumar \& Tarleton 1998) and are recruited into the inflamed tissues. Upon antigen-stimulation, these effectors T cells secrete $\gamma$-IFN and TNF- $\alpha$ (Russo et al. 1988) and/or directly kill the class I MHC infected targets by apoptosis (Kumar \& Tarleton 1998, Andrade et al. 1999).

\section{RELATIVE ROLES OF T CELLS AND ANTIBODIES IN ADAPTIVE IMMUNITY}

After two decades of intense investigation, the relative contribution of $\mathrm{B}$ or $\mathrm{T}$ cells in acquired resistance was clarified (Tarleton et al. 1992, Kumar \& Tarleton 1998). Mice with B cell deficiency showed increased mortality rates at late stages of infection, indicating that antibody production, although secondary in importance to cellular immunity, is nonetheless important to acquired resistance as suggested by early studies performed by Krettli and Brener (1982). Interestingly the B cell deficient mice showed a delayed rise in the acute parasitaemia, suggesting that antibodies may actually enhance parasite virulence in early stages of infection. Depending on the isotype and antibody specificities stimulated early in the antibody response, opsonization may occur, thereby enhacing the uptake of the parasite by macrophages (Lages-Silva et al. 1987). At times when mac- 
rophage activation is transiently blocked by Th2type of cytokines (refer to the abortive cycles of amastigote replication, later in this text), opsonization may increase rather than diminish the parasite load. In contrast to B cell knockouts, mice lacking class I or class II MHC-restricted T cells died during the acute phase of the infection with the Brazil strain. Not surprisingly, the infection was even worsened in animals that were deficient in both class I and class II MHC expression. Interestingly, the tissue inflammatory responses were absent in mice with the MHC-II class deficiency and the animals succumbed to infection due to high parasite load. Taken together, these studies have demonstrated that effector $\mathrm{CD}_{4}^{+}$and $\mathrm{CD}^{+} \mathrm{T}$ cells are critically involved in the acute control of $T$. cruzi infection. Similar processes may occur in humans, given the evidence that HLA-A2 ${ }^{+}$chagasic patients (indeterminate form) often display antigen-specific CD8 ${ }^{+}$CTL in their peripheral blood (Wizel et al. 1998). The molecular mechanisms of target cell killing was recently investigated in infected mice (Kumar \& Tarleton 1998). These authors showed, somewhat unexpectedly, that mice with targeted deletion of genes encoding for perfurin or granzyme B could control T. cruzi (Brazil strain) infection as efficiently as wild type animals. Their data suggest that class I MHC restricted $\mathrm{CD} 8^{+} \mathrm{T}$ cells may kill T. cruzi infected targets using the Fas/Fas L interaction system, or alternatively engage TNF- $\alpha$ and IFN- $\gamma$ cytokines in this process.

\section{T. CRUZI PROTEASES AS FACTORS OF VIRULENCE AND PATHOGENICITY}

In spite of the evidence indicating that tissue parasite burden correlates with the intensity of focal immunopathology, non-infected cells are sometimes also damaged in the proximity of the primary site of infection (Andrade ZA, this volume). Ribeiro dos Santos and Hudson (1980) were the first to propose that the passive adsorption of $T$. cruzi antigens onto certain types of non-infected host cells may render them susceptible to bystander antibody-dependent cellular cytotoxicity (ADCC). In addition to being possibly involved in the peripheral neuropathy which occurs in the acute phase (Koberle et al. 1968), ADCC may be involved in the microangiopathy which develops in acutely infected dogs (Andrade et al. 1994). Although the molecular basis of these lesions is still unknown, recent studies on the cysteine-proteinases of the cruzipain family (Cazzulo et al. 1989, Murta et al. 1990, Eakin et al. 1992, Meirelles et al. 1992, McKerrow et al. 1995) may offer new clues to investigate the underlying mechanisms. Originally identified because of their antigenic properties in chagasic patients (Scharfstein et al.
1983, 1986, Murta et al. 1990, Gazzinelli et al. 1990, Arnholdt et al. 1993, Morrot et al. 1997), the members of the cruzipain family consist of a heterogeneous group of closely related proteinase isoforms (Lima et al. 1994) encoded by about 130 genes (Campetella et al. 1992). The expression of the major isoform (cruzipain) is upregulated when the invading trypomastigotes transform into intracellular amastigotes (Tomas \& Kelly 1996) and this process is accompanied by increased cell surface expression. It is thus conceivable that the amastigotes, once released into interstitial spaces, may use the cell surface cruzipain isoenzymes to degrade the adjacent extracellular matrix (ECM). By doing so, the parasite may prevent or disrupt ECM-interactions with TNF- $\alpha$, chemokines and other inflammatory mediators involved in the recruitment and/or activation of immune cells T cells (Gillat et al. 1996). Cruzipain is worth studying in this context (Fig. 1), because antigenic deposits of this antigen were recently identified in sites of myocardial inflammation, in autopsies from patients with severe chronic cardiomyopathy (Morrot et al. 1997). Given that some of the cruzipain isoenzymes are stable and enzymatically active in neutral-acid $\mathrm{pH}$, we reasoned that their half-life in extracellular tissues would possibly depend on the levels of host proteinase inhibitors which permeate inflammatory sites. We thus sought to investigate the immunological implications of cruzipain interactions with $\alpha 2$-Macroglobulin, a non-specific plasma proteinase inhibitor (Morrot et al. 1997). In view of previous evidences indicating that $\mathrm{CD} 4^{+}$ $\mathrm{T}$ cells from chagasic patients responded to cruzipain (Arnholdt et al. 1993), we verified if the functional inactivation of the proteinase by $\alpha 2 \mathrm{M}$ could influence the efficiency of antigen presentation and processing by human monocytes. Our studies revealed that monocytes engage a highly endocytic scavenger receptor expressed by monocytes (CD91 or LRP/ $\alpha 2 \mathrm{MR})$ to rapidly internalize $\alpha 2 \mathrm{M}$-cruzipain complexes. The enhanced endocytic uptake of cruzipain-complexes ultimately favor increased intracellular processing and presentation of cruzipain peptides to $\mathrm{CD} 4^{+} \mathrm{T}$ cells (Morrot et al. 1997). Because $\alpha 2 \mathrm{M}$ binds to cell surface proteinases from amastigotes (Coutinho et al. 1997), it is conceivable that the multifunctional $\mathrm{LRP} / \alpha 2 \mathrm{MR}$ scavenger receptor may promote the uptake of amastigotes coated with $\alpha 2 \mathrm{M}$ ligated to cruzipain, in ways that are reminiscent of mechanisms recently described for the macrophages' mannose receptor (Khan et al. 1995). In both cases, the efficiency of antigen-presentation of amastigotes epitopes to T cells may be potentiated. In short, our studies illustrate how interactions between parasite proteinases and host inhibitors may 
integrate elements of innate defense systems with those in charge of acquired immunity.

As a follow-up from the studies involving $\alpha 2 \mathrm{M}$, we turned our attention to kininogen (HK or LK), both of which are members of the cystatin superfamily of cysteine proteinase inhibitors (Barret et al. 1986). In addition to the cystatin-like domains, these multifunctional plasma glycoproteins (HK) participates in the activation of the intrinsic pathway of coagulation and modulate platelet activation by thrombin. Important to our discussion, HK or LK are the parent substrate molecules from which bradykinin or lysil-bradykinin are released, upon proteolytic cleavage respectively by plasma or tissue kallikrein (Bhoola et al. 1992).

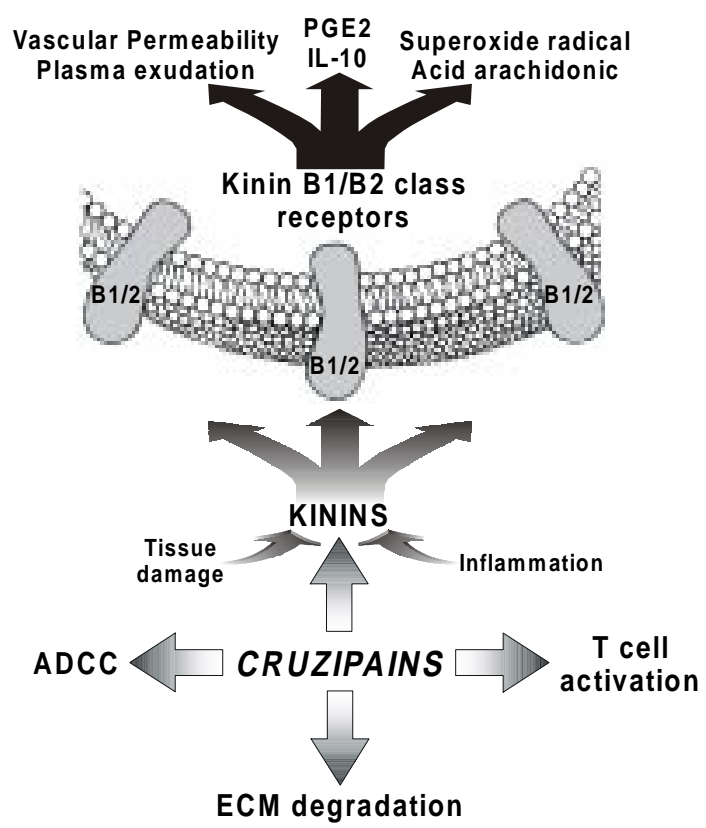

Fig. 1: mechanisms of cruzipain-induced immunopathology The illustration depicts the multifunctional roles that cruzipainisoforms may play when tissues are exposed to parasites which were prematurely released from dead target cells. Expressed in high levels by amastigotes, cruzipain was recently identified in sites of myocardial inflammation in autopsies obtained from patients with chronic cardiomyopathy (Morrot et al. 1997). Cruzipain-isoforms secreted or leaked into interstitial spaces can (i) trigger humoral and cellular immune responses (Scharsftein et al. 1983, Arnholdt et al. 1993); (ii) degrade adjacent ECM; (iii) promote the release of vasoactive kinins (Del Nery et al. 1997). These processes can be, to some extent, modulated by interactions with host proteinase inhibitors which permeate the inflammatory site. Cruzipain complexes with $\alpha 2 \mathrm{M}$ potentiate $\mathrm{CD}^{+}{ }^{+} \mathrm{T}$ cell responses (Morrot et al. 1997). Vasoactive kinins can be generated upon proteolytic processing of kininogen (Del Nery et al. 1997). Triggering of B1/B2 subtypes of G-protein coupled kinin-receptors expressed by vascular endothelial cells or smooth muscle can increase the permeability of post-capillary venules (Svensjo et al. 1997) and induce vasodilation. The induction of NO and/or PGE2 by endothelial cells and macrophages may down-regulate the inflammatory response in lymphoid tissues.
Kinins are short-lived peptides which engage distinct subtypes of G-protein coupled (GPC) kinin receptors in a wide spectrum of biological processes, such as modulation of neuronal activity (Higashida et al. 1990), cell proliferation and vascular permeability (Bhoola et al. 1992), smooth muscle contraction or relaxation (Monbouli \& Vanhoutte 1995). Depending on the host cell, kinin signaling is transduced by GPC-receptors that are either expressed constitutively (B2) or are induced (B1) during anoxia or noxious stimuli (Regoli 1980, Burch \& Kyle 1992).

The initiative to investigate the relationship of T. cruzi with the kinin system was initially motivated by enzymatic specificity studies carried out with cruzipain 2 (Lima et al. 1994), a minor isoform whose recombinant form was only recently expressed in S. cerevisae. After noting that its substrate specificity somewhat resembled that of tissue kallikrein, we were able to demonstrate that these isoforms could act as kinin-releasing enzymes. (Del Nery et al. 1997), although with different efficiency. On a first look, the finding that cruzipain was able to proteolyze HK/LK seemed paradoxical because these plasma glycoproteins were previously reported to inactivate cruzipain by means of their tight-binding cystatin domains (Stoka et al. 1995, Scharfstein et al. 1995). Clues to understand the mechanism of kinin-release emerged when the Ki's obtained for HK were determined for different isoforms of cruzipain: interestingly, we observed that r-cruzipain 2 was markedly less sensitive to inhibition by $\mathrm{HK}$ as compared to cruzain (Lima et al. in preparation) the archetype from the cruzipain family (McKerrow et al. 1995). Our data suggest that the kininogenase activity of $T$. cruzi cysteine-proteinases might have evolved due to structural diversification of the catalytic site of some isoforms, such as cruzipain 2. Notably, in the same study (Del Nery et al. 1997) we also showed that cruzipain could generate bradykinin indirectly, that is, by converting the plama prekallikrein zymogen in active kallikrein. In a parallel study, we used intravital microscopy to verify if the topical application of purified cruzipain on the hamster cheek pouch could stimulate increases in vascular permeability (Svensjo et. 1997). Potent responses were indeed observed, suggesting that $T$. cruzi may use cruzipain isoezymes to generate kinins upon cellular contact with endothelial cells (Fig. 1). Ongoing studies in mice with targeted deletion of kinin-receptors should confirm if this hemoflagellate actively engages the kallikrein-kinin system to migrate across non-fenestrated blood capillaries.

The role of $T$. cruzi-induced kinin release in the pathogenesis of chronic heart disease, previ- 
ously suggested on the basis of animal studies (Morris et al. 1990, Rossi 1990) is worth exploring. In a detailed three-dimensional confocal microscopy analysis of post-necropsy heart specimens derived from chronic chagasics autopsies, Higuchi et al. (1999) have noted extensive abnormalities of cardiac microcirculation as well as in the interstitial matrix patterns of myocardial tissues. Peculiar lesions, often manifested as arteriolar dilatation and capillary vessel tortuosity, were described, being thus far vaguely attributed to fibrosis and/or to as yet uncharacterized lesions induced by the parasites. Apart from initial studies looking at effects of desialilation by TS enzymes (Libby et al. 1986), little is known about the biochemical basis of T. cruzi interaction with endothelial cells (Morris et al. 1990). As discussed earlier in this section, the realization that cruzipain-isoenzymes are capable of releasing pro-inflammatory kinins offers a new experimental framework to investigate the pathophysiological consequences of long-term stimulation of myocardial capillaries by vasoactive kinins. Our description of cruzipain effects on the microcirculation of the hamster cheek pouch (Svensjo et al. 1977) suggest that merely a few parasites may suffice to generate vasoactive kinins, thereby provoking plasma exudation from vicinal capillaries (Fig. 2, bottom panel). Similar processes, perhaps involving NO released by endothelial or smooth muscle cells may underlie the neuronal lesions observed in the acute stage of infection.

\section{SUBVERSION OF THE CLASS I MHC PATHWAY OF ANTIGEN PRESENTATION IN T. CRUZI INFECTED CELLS}

During microbial infection, host class I or class II molecules encoded by polymorphic MHC genes bind to antigenic peptides (T epitopes) produced by the invasor. Once associated with the appropriate MHC allele product, the peptide:MHC complex is targeted to the cell surface of the infected cell, where it is "presented" to naive or effector T cells. The intracellular pathways that generate small antigenic peptides by proteolytic processing and then enable MHC loading are collectively referred as antigen processing and presentation system. In the past years, the multiple checkpoints that are sensitive to attack by virus and other intracellular parasites were characterized. In general terms, the viral products may target elements controlling (i) antigen-proteolysis by proteosomes, (ii) peptide transport to the ER (iii) MHC assembly and/or sorting and (iv) surface expression of class I MHC:peptide complexes.

As shown in mice, the analysis of HLA-A2restricted CTL specificities in the peripheral blood of chagasic patients has identified different members of a subfamily of TS-related antigens as killer cell targets (Wizel et al. 1997, Low et al. 1997): two originating from amastigote-derived antigens, ASP-1 and ASP-2, and one from trypomastigotespecific antigen, TSA-1. Teleologically, the usage of a vast array of polymorhic $T$. cruzi proteins as parent substrates for the proteosomal proteases makes sense because this should increase opportunities for epitope loading of the highly diverse MHC-class I products that exist in genetically outbred populations. In other words, had the antigen variability involved exclusively single genes, the parasite sub-populations which display variant sequences should have increased chances to escape from detection. Thus, structural variability imported by multi-copy polymorphic genes may have been advantageous to host-parasite equilibrium because it should reduce the excessive risk associated with the growing diversification of parasite sub-populations.

The maneuvers which some $T$. cruzi clones use to subvert the class I presentation pathway are not clarified as yet. In a recent study focusing on class II MHC restricted CD4+ responses of inbred mice, Kahn and Wlekinski (1997) offered insight into this problem. They showed that the simultaneous expression of individual antigens from polymorphic TS subfamily may limit the availability of processed epitopes from each antigen below the threshold level required to stimulate a protective IFN- $\gamma$ response against the parasite. It will be interesting to know if similar mechanisms may allow for parasite escape from detection by class IMHC restricted killer T cells. Admittedly, however, antigen variation per se may not ensure protection to parasites that are multiplying in host cells from genetically outbred individuals (e.g. dogs and humans), because in such cases antigen-presentation can involve a more diversified array of MHC allelic products. As discussed in the next section, there are reasons to think that amastigotes may be equipped with the molecular machinery required to subvert the class I MHC presentation pathway.

\section{T. CRUZI CLONAL DIVERSITY AND AMASTIGOTE EVASION MECHANISMS}

Target recognition of amastigote-antigens by class I MHC killer CTL is likely the most effective means to curtail the progression of intracellular infection, because cell death would occur before the parasites can transform into infective trypomastigotes. The selective pressure which these killer $\mathrm{T}$ cells exert on the intracellular amastigotes must be particularly strong in individuals from genetically outbred populations. Because 
the rates of intracellular division and transforming efficiency of amastigotes vary significantly among different clones (Dvorak \& Hyde 1973, Revollo et al. 1998), the host cell ability to generate antigenic peptides to class I MHC molecules may be subjected to similar constraints. Perhaps a given subpopulation of amastigote clones may be more apt to subvert the class I MHC presentation pathway if they multiply slowlier. By reducing their metabolism, the availability of amastigote antigens (e.g., ASP) in the host cell cytoplasm may be also decreased; under these conditions, antigenic peptides from the slowly growing amastigotes (latent forms) may not reach the threshold required to load class I MHC molecules. Conversely, sub-populations of amastigote clones which exhibit high rates of amastigote division should be able to release high contents of polymorphic antigens into the cytosol, thus allowing for efficient presentation of antigenic peptides at the target cell surface. It is thus conceivable that tissues from chronically infected outbred individuals may harbor a small number of slowly dividing clones that tend to escape from amastigote-specific killer T cells. As discussed later on, we propose that these parasite subpopulations may contribute to the exacerbation of immunopathology. Of course, parasite clones that sustain a high levels of proliferation may also succeed at subverting the class I MHC pathway, but in this case they must actively block antigen proteolysis, peptide transport or cell surface exposure of the class I MHC:peptide complex at the target cell surface, by analogy to mechanisms described for virus.

\section{DUAL ROLE OF TRYPOMASTIGOTE-SPECIFIC KILLER T CELLS}

On a first impression, the ability of CTL to kill non-phagocytic targets which harbor intracellular trypomastigotes would seem to be a redundant process, because most of the infective parasites should be anyway released into the extracellular fluids upon host cell burst. However, target cell death by apoptosis should be advantageous to the host (Andrade et al. 1999), inasmuch as this mechanism would spare host tissues from the detrimental effects of necrosis that would otherwise occur if the target cells collapse due to excessive numbers of parasites. Since mutual destruction is not a fruitful evolutionary strategy, it is unlikely that host cell apoptosis also destroys all the intracellular parasites. During stages of chronic infection, the large majority of infected cells should harbor parasites derived from a single parasite clone. Since amastigote division proceeds asynchronously (Dvorak \& Hyde 1973), the clones which succeed at subverting the class I antigen presentation path- way should gradually transform into trypomastigotes. The trypomastigote specific CTL may then attack the target cells as soon as the antigenic peptide epitopes (originating from TS-related or other dominant antigens) reach the threshold required for class I MHC presentation. Although the rates of MHC-loading and surface expression may vary from one type of host cell to another, it is reasonable to predict that the most infected target cells should still harbor some intracellular amastigotes by the time the trypomastigote-specific CTL induced death by apoptosis. Killing at early stages of trypomastigote-transformation makes sense because the antigen presentation machinery may not be functional at later stage of the intracellular cycle. Therefore, an early attack by trypomastigote-specific killers is the best possible compromise between the host and the parasite, because the release of just a few intracellular trypomastigotes should suffice to ensure long term survival of both. According to this model, the extent to which tissues are exposed to prematurely released amastigotes should be critically influenced by the time course of target cell recognition by trypomastigote specific killer T cells. In short, we predict that high numbers of prematurely released amastigotes should be exposed to tissues when (i) the class I MHC presentation of amastigote-antigens is subverted or, alternatively, when amastigote-specific CTL are either deleted or down-regulated, (ii) trypomastigote-specific killers attack host cells as soon as the trypomastigotes are transformed. Our model sustains that pathogenic sub-populations of trypomastigote clones should maximize (rather than minimize, as postulated for amastigotes) antigen presentation by the class I MHC presentation pathway.

\section{ABORTIVE-CYCLES OF AMASTIGOTE REPLI- CATION: ROLE OF CLASS I MHC-KILLER T CELLS}

As discussed above, trypomastigote specific killer $\mathrm{T}$ cells can abort the intracellular development of a fraction of the parasites. Once released to extracellular spaces, the trypomastigotes tend to move away from the primary foci of infection, while the non-motile extracellular amastigotes [which resist C' mediated lysis (Iida et al. 1989)] tend to accumulate in the proximity of the primary site of infection (Fig. 2) . Of necessity, there is only one obvious pathway that may permit the survival of these extracellular amastigotes: the maintenance of a suppressive environment, due to the activity of TGF- $\beta$ or IL10, or other mediators. If spared from death, the amastigote may leave the parasitophorous vacuole and lodge in the cytosol, where they actively proliferate (Ley et al. 1988). As previously discussed, we postulate that some 
amastigote clones may succeed in subverting the class I MHC presentation pathway. Hence, the killing of target cells by CTL (secreting type 2 cytokines, Tc2) specific for trypomastigote peptides may release a substantial number of amastigotes into the interstitium. New cycles of abortive replication may ensue, as the extracellular amastigotes infect macrophages that are recruited into the primary site of infection. Our model (Fig. 2) predicts that the ultimate fate (death or replication) of the intracellular amastigotes lodged in the macrophages should be determined by the local balance between cytokines released by activated Th1 or Tc1 (eg. IFN- $\gamma$, TNF- $\alpha$ ) and macrophage down-regulatory cytokines (IL-10 and TGF- $\beta$ ) released by Tc $2 /$ Th 1 cells or by equivalent cytokines released by $\mathrm{Tc} 2 \mathrm{CD} 8^{+}$lymphocytes. As discussed earlier in this text, macrophage stimulation by parasite-factors which induce PGE2 may down-regulate the pro-inflammatory response otherwise elicited by by t-GPI-mucins (Procopio et al. in press).

In the acute infection, the tissue parasite load in lymphoid organs, such as the spleen, is initially high but it tends to decrease as cellular immune effectors intervene. It is possible that the extracellular amastigotes which are prematurely released from host cells, due to attack by trypomastigotespecific CTL, may somehow contribute to the massive polyclonal activation of lymphocytes (D'Imperio-Lima et al. 1985) and/or to the transient state of non-specific immunosuppression (Teixeira et al. 1978). Interestingly, there is a close temporal relationship between the drop in tissue parasite load and the onset of the immunoregulatory changes which occur in peripheral lymphoid tissues (Dos Reis 1997). It is thus possible that the pool of spleen $\mathrm{CD}^{+} \mathrm{T}$ cells which undergo activation-induced cell death (AICD) upon in vitro stimulation with anti-CD3 (Dos Reis et al. 1995) is enriched by amastigote-specific $\mathrm{CD} 4^{+} \mathrm{T}$ cells. The recent demonstration that macrophages exposed to live amastigotes activate $\mathrm{CD} 4^{+}$and $\mathrm{CD} 8^{+}$ $\mathrm{T}$ cells from lymph nodes and spleen (CauladaBenedetti et al. 1998) is consistent with the above mentioned concept. As pointed out by Dos Reis et al. (1997), the polarization of Th2-type responses at late stages of the acute infection may occur due to the elimination of activated Th1-type cells by apoptosis. It will be interesting to determine if the accumulation of amastigote-derived antigens is a pre-requisite for the induction of anergy, clonal deletion and/or Th2-dependent down-regulation of amastigote-specific CD4 ${ }^{+}$Th1 lymphocytes (Fig. 2, upper panel). If true, animals or patients which exhibit deficit in trypomastigote-specific CTL
(Tc2) would not be able to release substantial numbers of intracellular amastigotes to lymphoid tissues. Under these hypothetical conditions, amastigote-specific $\mathrm{CD}^{+}$Th1 cells would not be as efficiently eliminated or down-regulated and the Th1 inflammatory subset would expand, thereby aggravating tissue damage. These general predictions are consistent with recent data suggesting that early immunological events can influence the development of inflammation at chronic stages of infection (Mariano et al. 1999). Perhaps the hypothesis outlined here (Fig. 2 upper panel) may offer clues to understand the mechanisms underlying the contrasting behavior of the Colombiana-Balb/C model of chronic carditis (Ribeiro dos Santos et al. 1992). Instead of the $\mathrm{CD}^{+} \mathrm{T}$ cells (anti-parasite) which dominate the chronic myocardial infiltrates in the majority of mice models (Tarleton et al. 1997) as well as in humans (Reis et al. 1997), the infection of Balb/C mice with Colombiana favors the induction of autoreactive $\mathrm{CD}^{+} \mathrm{T}$ cell effectors which attack cardiac tissues. According to our model, the Balb/ $\mathrm{C}$ animals infected by the Colombiana strain may have failed to efficiently eliminate or down-regulate cross-reactive amastigote-specific Th $1 \mathrm{CD}^{+}$ cells in lymphoid tissues, perhaps because trypomastigote-specific $\mathrm{CD} 8^{+} \mathrm{T}$ cells ( $\mathrm{Tc} 2$ ) are not functionally active in this model, at least so in the chronic stages of infection. Our hypothesis also predicts that the self-epitopes recognized by these $\mathrm{CD}^{+}$Th1 cell clones should cross react with amastigote antigens from the Colombiana strain.

Although the involvement of polarized $\mathrm{CD} 8^{+}$ cells from the Tc2 subset has not been demonstrated in $T$. cruzi infection, in other settings (Cerwenska et al. 1998) they were shown to produce IL-4, IL5 and IL-10, while sustaining the capacity to act as cytotoxic $\mathrm{T}$ cells upon re-stimulation. It has been recently proposed that the conversion of $\mathrm{Tc} 1$ into Tc2 suppressors depends on the NO releasing activity of macrophages, which is in turn stimulated by Th1 lymphocytes. It is believed that the cytokine profile of Tc2 may ensure that target cell apoptosis proceeds without the characteristic necrosis and tissue injury associated with the activity of CTL from the Tc1 subset (Kolb et al. 1998). In a recent study of PBMC responses, Bahia-Oliveira et al. (1998) observed that type 2cytokines predominate in the indeterminate stage of the human disease, while type 1 cytokines are more frequently observed in symptomatic individuals. It will be important to know if Tc2 and Tc1 contribute to these fluctuations, and assess their relationship to the distribution of cellular infiltrates in the myocardial tissues (Higuschi et al. 1993). 


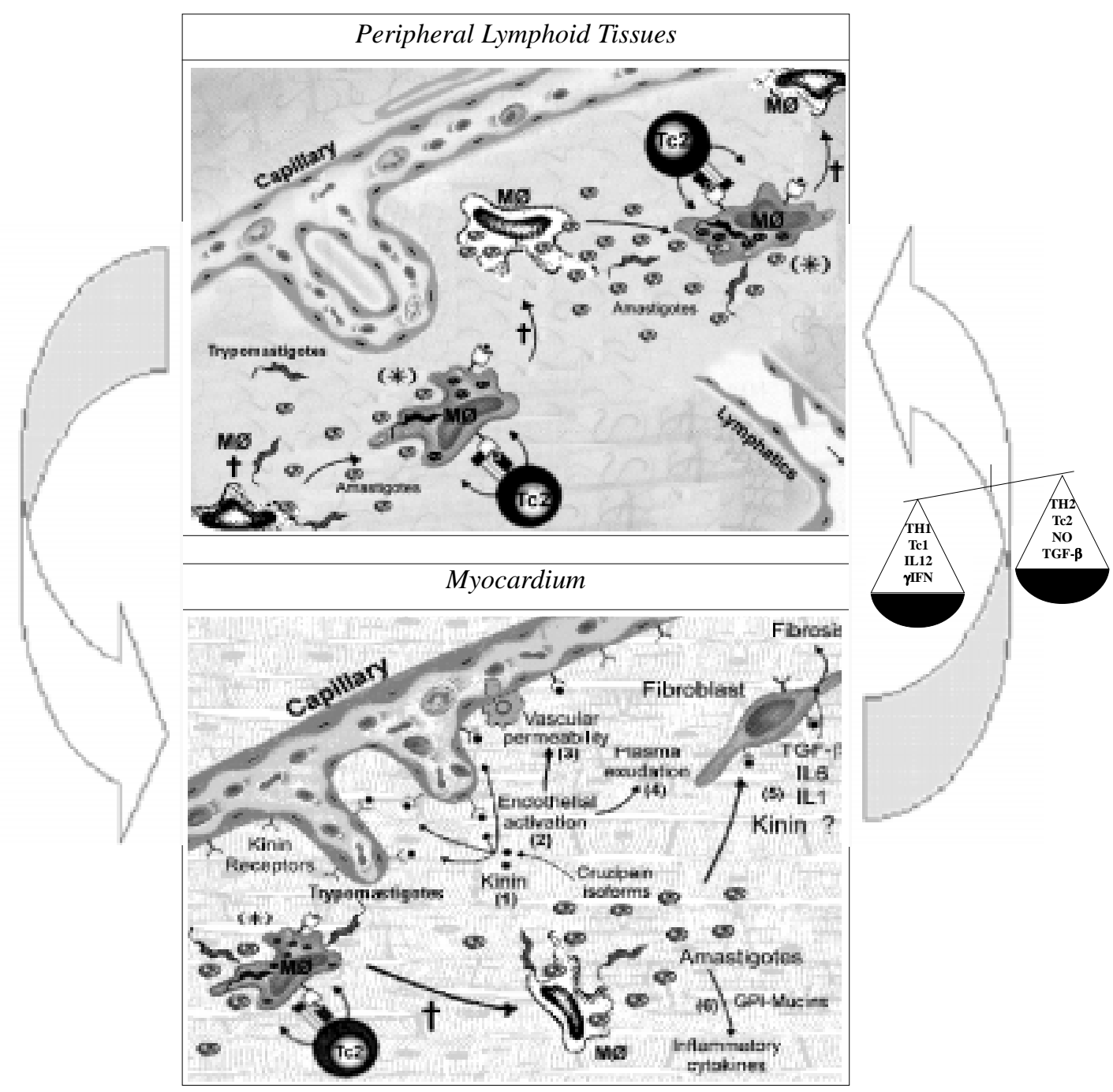

Fig. 2: role of abortive cycles of amastigote replication in the immunopathology of Chagas disease. The model predicts that the blockade of macrophage activation by anti-inflammatory cytokines (IL10 and/or TGF- $\beta$ ) allows for the replication of amastigotes in the cytosol (S). Some amastigote clones can subvert the class I MHC antigen-presentation pathway, thus avoiding immune detection by amastigote-specific killer T cells. As soon as the first trypomastigotes are transformed, peptide-antigens from these forms are generated in the host cell cytoplasm. The peptide:MHC complex is displayed at the cell surface of the macrophages, propitiating the attack by trypomastigote-specific Tc2 killer cells ( $\mathbf{t})$. Because amastigote division is asynchronous, the macrophages still harbor several intracellular amastigotes at the time of attack by trypomastigote-specific killer $\mathrm{T}$ cells. Extracellular amastigotes are then released to the interstitium, together with a few trypomastigotes. While the trypomastigotes move away from the site of infection, the nonmotile amastigotes stay in the periphery. The extracellular amastigotes are then opsonized and rapidly internalized by tissue macrophages, which are kept suppressed by IL-10 and/or TGF- $\beta$ released by Th2-type of cells, or by Tc 2 effectors. These cytokines again prevents macrophage activation, allowing for amastigote escape into the cytosol, where they start to multiply. Once again, the amastigotes subvert the class I MHC presentation pathway, and consequently, are not recognized by amastigote-specific killer cells. Several rounds of abortive-infection are induced by trypomastigote-specific killers $(\mathrm{Tc} 2)$ [(* $\rightarrow \mathbf{t})]$. This feedback loop may persist for some time, allowing for the build up of amastigote-antigens and pro-inflamatory products inside dead macrophage bodies. It is proposed that the onset of the class I MHC-restricted abortive cycles of amastigote replication in lymphoid tissues (upper panel) may indirectly play a role in immunoregulation (refer to text). In the myocardium (right panel), this pathway may be involved in the exacerbation of the focal inflammatory responses, precipitating the transition from the indeterminate form to the chronic form of the disease. Immunopathology is exacerbated due to the local deposition of antigens and/or proinflammatory products from pathogenic amastigotes. Living amastigotes are not be readily visualized in histological sections because they are constantly released and internalized by macrophages. Multiple molecular factors could contribute to the aggravation of myocardial tissue injury. For example, the kinin-releasing activity of cruzipain isoforms (1) could activate vascular endothelial cells (2), thus increasing vascular permeability (3) and promote plasma exudation (4). At some critical stage, the proinflammatory activity of GPI-mucins (6) could stimulate an incipient wave of Th1-response in the myocardial tissues, which would be promptly followed by a dominant regulatory Th2/Tc2-response (TGF- $\beta$, IL6) (5). The arrows linking the two panels highlights the importance of the peripheral lymphoid organ function (left panel) in the maintenance of the immunological homeostasis. 


\section{ROLE OF CD8 ${ }^{+}$KILLERS IN THE EXACERBATION OF CHRONIC IMMUNOPATHOLOGY}

Andrade et al. (1997) have recently demonstrated that the canine model accurately reproduces the main features of the indeterminate form of human Chagas disease. They suggested that the heart lesions in the indeterminate stage of the disease are caused by selflimited cycles of focal inflammatory changes, probably determined by subtle shifts in the immunoregulatory activity of effector T lymphocytes. The canine model does not seem to support an obvious role for microvascular lesions in this stage of the disease. In contrast to the progressive nature of he chronic carditis observed in mice, the transition from indeterminate to chronic heart disease in dogs is not gradual. In humans, the distribution of cytokine-producing cells in myocardial tissues revealed that $\mathrm{Th} 2$ type cells are usually associated with higher deposition of parasite antigens (Higuchi et al. 1993, Reis et al. 1997).

Here the concept of a "pathogenic" clone is defined in the operational sense: it refers to an opportunistic population of intracellular amastigotes that somehow exploits antigen variation to subvert the class I presentation of target cells which express a given MHC-haplotype. In other words, a pathogenic clone isolated from one chronically infected individual (outbred species) would not necessarily induce pathology in individuals that express a different MHC haplotype. As explained earlier in this article, subversion of class I pathway of antigen presentation should occur more frequently in inbred mice than in humans, or dogs, because the murine host cells only count with a limited number of MHC alleles to counteract the extreme antigen variability of the intracellular parasites. We may thus predict that the "pathogenic" parasite sub-populations are kept at very low numbers in tissue reservoirs because the selective pressure exerted by amastigote-specific killer T cells in heterozygous individuals is very strong. The "pathogenic" clones may only escape from amastigote-specific CTL by infecting suppressed macrophages, the latter state being dictated by the modulatory influence of type- 2 cytokines which dominate the PBMC responses of patients during the indeterminate stage of the disease (BahiaOliveira et al. 1998).

From where do these parasites clones come from? As already mentioned, extracellular amastigotes, once prematurely released from killed target cells in any tissues, may persistently infect resident macrophages, using to this end the alternative pathway of invasion (Ley et al. 1988). Organs that usually maintain macroph- ages in a relatively supressed state (eg. adrenal glands, Teixeira et al. 1977) may favor the outgrowth of these potentially pathogenic amastigote clones. In a period of a relatively profound immuno-suppression, perhaps the threshold required for amastigote-epitope presentation by the class I presentation pathway is no longer reached in the suppressed macrophage. Because they are not detected by amastigote-specific killer T cells, the intracellular amastigotes can then transform into trypomastigotes. After being recognized by trypomastigote-specific CTL, the target cell is killed, and the parasites are prematurely released into the interstitium. Those that had differentiated into trypomastigotes fall into the circulation and eventually reach the myocardium by traversing blood capillaries which already express adhesion molecules (Zhang \& Tarleton 1996). After lodging inside a cardiac fiber, or in a tissue macrophage (Fig. 2, bottom panel) these parasites again subvert the class I MHC presentation, thus avoiding recognition by amastigotespecific killer T cells. As the first trypomastigotes transform, the target cell is again killed by trypomastigote-specific Tc 2 killer $\mathrm{T}$ cells. The fraction of intracellular amastigotes that had not transformed into trypomastigotes is then once again released into the interstitium. Successive rounds of invasion and abortive cycles of infection in suppressed macrophages then cause the progressive accumulation of amastigote-antigens and/or their pro-inflammatory products, such as GPI-mucins, inside dead macrophages (apoptotic bodies). In organs that are highly vascularized, such as the heart, cruzipain-isoenzymes secreted or leaked by $T$. cruzi amastigotes can process kininogen, thus releasing pro-inflammatory kinins. By acting on adjacent endothelial cells, these vasoactive peptides may induce plasma exudation, thereby expanding the inflammatory response, and contributing to interstitial fibrosis. The chemokines released by tissues exposed to tGPI-mucins and other pro-inflammatory mediators might also differently recruit autoreactive $\mathrm{CD}^{+}$or $\mathrm{CD} 4^{+}$lymphocytes (Cunha-Neto et al. 1996) into the myocardium, thus aggravating chronic immunopathology.

\section{ACKNOWLEDGMENTS}

To Dr George dos Reis for helpful comments made while reading this manuscript.

\section{REFERENCES}

Affranchino JL, Ibanez CF, Luquetti AO, Rassi A, Reyses MB, Macina RA, Aslund L, Pettersson U, Frash ACC 1989. Identification of a Trypanosoma cruzi antigen that is shed during the acute phase of 
Chagas' disease. Mol Biochem Parasitol 34: 221228.

Aliberti JC, Cardoso MA, Martins GA, Gazzinelli RT, Vieira LQ, Silva JS 1996. Interleukin-12 mediates resistance to Trypanosoma cruzi in mice and is produced by murine macrophages in response to live trypomastigotes. Infect Immun 64: 1961-1967.

Andrade SG, Andrade Z 1966. Estudo histopatológico comparativo das lesões produzidas por 2 cepas do Trypanosoma cruzi. O Hospital 70: 1268-1278.

Andrade ZA, Andrade SG, Correa R, Sadigursky M, Ferrans VJ 1994. Myocardial changes in acute Trypanosoma cruzi infection: ultrastructural evidence of immune damage and the role of microangiopathy. Am J Pathol 144: 1403-1411.

Andrade ZA, Andrade SG, Sadigursky M, Wenthold RJ Jr, Hilbert SL, Ferrans VJ 1997. The indeterminate phase of Chagas' disease: ultrastructural characterization of cardiac changes in the canine model. Am J Trop Med Hyg 57: 328-336.

Andrade ZA, Zhang YuZX, Andrade SG, Takeda K, Sadigursky M, Ferrans VJ 1999. Apoptosis in a canine model of acute Chagasic myocarditis. $\mathrm{J} \mathrm{Mol}$ Cell Cardiol 581-596.

Andrade LO, Machado CMS, Chiari E, Pena SDJ, Macedo AM 1999. Role of parasite and host genetic backgrounds in the differential tissue tropism of Trypanosoma cruzi strains (this volume).

Arnholdt AC, Piuvezam MR, Russo DM, Lima AP, Pedrosa RC, Reed SG, Scharfstein J 1993. Analysis and partial epitope mapping of human $\mathrm{T}$ cell responses to Trypanosoma cruzi cysteinyl proteinase. J Immunol 15: 3171-3179.

Bahia-Oliveira LM, Gomes JA, Rocha MO, Moreira MC, Lemos EM, Luz ZM, Pereira ME, Coffman RL, Dias JC, Concado JR, Gazzinelli G, CorreaOliveira R 1998. IFN-gamma in human Chagas' disease: protection or pathology? Braz J Med Res 31: 127-131.

Barret AJ, Rhawlings ND, Davies ME, Machleidt W, Salvesen G, Turk V 1986. In AJ Barret \& G Salvesen (eds), Proteinase Inhibitors: Cysteine-proteinase Inhibitors of the Cystatin Superfamily, p. 515-569. Elsevier, Amsterdam.

Bhoola KD, Figueroa CD, Worthy K 1992. Bioregulation of kinins: kallikreins, kininogens, and kininases. Pharmacol Rev 44: 1-80.

Brener 1965. Comparative studies of different strains of Trypanosoma cruzi. Ann Trop Med Parasitol 59: 1926.

Burch RM, Kyle D 1992. Recent developments in the understanding of bradykinin receptors. Life Sci 50: 829-838.

Burleigh B, Andrews NW 1998. Signaling and host cell invasion by Trypanosoma cruzi. Curr Opin Microbiol 1: 461-465.

Camargo MM, Almeida IC, Pereira ME, Ferguson MA, Travassos LR, Gazinelli RT 1997. Glycosylphosphatidylinsitol-anchored micin-like glycoproteins isolated from Trypanosoma cruzi trypomastigote initiate the synthesis of proinflammatory cttokines by macrophages. J Immunol 158: 5890-5901.
Cazzulo J, Cousi R, Raimondi A, Wernstedt C, Hellman U 1989. Further characterization and partial amino acid sequence of a cysteine protease (cruzipain) from Trypanosoma cruzi. Mol Biochem Parasitol 33: 3342.

Campetella O, Henrickson J, Aslund L, Frasch ACC, Petterson U, Cazzulo JJ 1992. The major cysteine protease (cruzipain) is encoded by multiple polymorphic tandemly repeated organuzed genes located in different chromossomes. Mol Biochem Parasitol 50: 225-234.

Cardillo F, Voltarelli, JC, Reed SG, Silva JS 1996. Regulation of Trypanosoma cruzi infection in mice by gamma interferon and interleukin 10: role of NK cells. Infect Immun 64: 128-134.

Cerwenka A, Carter LL, Reome, JB, Swain, SL, Dutton RW. 1998. In vivo persistence of CD8 polarized T cell subsets producing type 1 or type 2 cytokines. $J$ Immunol 161: 97-105.

Colli W 1993. Trans-sialidase: a unique enzyme activity discovered in the protozoan Trypanosoma cruzi. FASEB J 7: 1257-1264.

Cotta de Almeida V, Bertho AL, Villa Verde DM, Savino W 1997. Phenotypic and functional alteration of thymic nurse cells following acute $T$. cruzi infection. Clin Immunopath 82: 125-132.

Coutinho CMLM, Cavalcanti, GH, van Leuven, AraujoJprge, TC. 1997. Alpha-2 Macroglobulin binds to the surface of Trypanosoma cruzi. Parasitol Res 83:144-150.

Cunha-Neto E, Coelho V, Guilherme A, Fiorelli N, Stolf N, Kalil J 1996. Autoimmunity in Chagas' diseaseidentification of cardiac myosin-B13 Trypanosoma cruzi protein cross-reactive $\mathrm{T}$ cell clones in heart lesions of a chronic Chagas' cardiomyopathy patient. J Clin Inv 98: 1709-1712.

de Diego JA, Palau MT, Gamallo C, Penin P 1998. Relationships between histopathological findings and phylogenetic divergence in Trypanosoma cruzi. Trop Med Int Health 3: 222-233.

Del Nery E, Juliano MA, Lima APCA, Scharfstein J, Juliano L 1997. Kininogenase activity by major cysteinyl proteinase (Cruzipain) from Trypanosoma cruzi.J Biol Chem 272: 25713-25718.

D' Imperio Lima MR, Joskowicz M, Coutinho A, Kipnis T, Eisen H 1985. Very large and isotypically atypical polyclonal plaque-forming cell responses en mice infected with Trypanosoma cruzi. Eur J Immunol 15: 201.

Dos Reis GA 1997. Cell-mediated immunity in experimental Trypanosoma cruzi infection. Parasitol Today 13: 335-341.

Dvorak JA, Hyde TP 1973. Trypanosoma cruzi: interaction with vertebrate cells in vitro. Individual interactions at the cellular and subcellular levels. Experim Parasitol 34: 268-283.

Eakin AE, Mills AA, Harth G, McKerrow JH, Craik CS 1992. The sequence, organization and expresion of the major cysteine protease (cruzpain) from Trypanosoma cruzi. J Biol Chem 267: 7411-7420.

Gazzinelli RT, Leme VCM, Cançado JR, Gazzinelli G, 
Scharfstein J 1990. Identification and partial characterization of $T$. cruzi antigens recognized by T cells and immune sera from chagasic patients. Infec Immuni 58: 1437-1444.

Gazzinelli RT, Oswald IP, James SL, Sher A 1992. IL10 inhibits parasite killing and nitrogen oxide production by IFN-gamma-activated macrophages. $J$ Immunol 148: 1792-1796.

Gillat D, Cahalon L, Hershkoviz R, Lider O 1996. Interplay of $\mathrm{T}$ cells and cytokines in the context of enymatically modified extracellular matrix. Immunol Today 17: 16-20.

Giordano R, Chammas R, Veiga SS, Colli W, Alves MJ 1994. An acidic component of the heterogeneous Tc85 protein family from the surface of Trypanosoma cruzi is a laminin binding glycoprotein. Mol Biochem Parasitol 65: 85-94.

Higuchi ML, De Brito T, Reis MM, Barbosa A, Bellotti G, Pereira Barreto AC, Pileggi F 1993. Correlation between Trypanosoma cruzi parasitism amd myocardial inflammatory infiltrate in human chronic chagasic myocarditis: light microscopy and immunohistochemical findings. Cardiov Pathol 2: 101106.

Higuschi ML, Fukasawa S, De Brito T, Parzianello LC, Bellotti G, Ramires JAF 1999. Different microcirculatory and intestinal matrix patterns in idiopathic dilated cardiomyopathy and Chagas' disease: a three dimensional confocal microscopy study. Heart 81 : 1-6.

Iida K, Whitlow NM, Nussenzweig V 1989. Amastigotes of Trypanosoma cruzi escape destruction by terminal complement components. J Exp Med 169: 881891.

Kahn SJ, Wleklinski M 1997. The surface glycoproteins of Trypanosoma cruzi encode a superfamily of variant T cell epitopes. J Immunol 159: 4444-4451.

Kahn SJ, Wleklinski M,Aruffo A, Farr A, Coder D, Kahn M 1995. Trypanosoma cruzi adhesion to macrophages is facilitated by the mannose receptor. $J$ Exp Med 182:1243-1258.

Koberle F 1968. Chagas' disease and Chagas' syndromes: the pathology of American trypanosomiasis. Adv Parasitol 6: 63-116.

Kolb H, Kolb-Bachofen V 1998. Nitric oxide in autoimmune disease: cytotoxic or regulatory mediator? Immunol Today 19: 556-561.

Krettli AU, Brener Z 1982. Resistance against Trypanosoma cruzi is associated to anti-living trypomastigote antibodies. J Immunol 128: 2009-2012

Kumar S, Tarleton RL 1998. The relative contribution of antibody production and CD8+ T cell function to immune control of Trypanosoma cruzi. Parasite Immunol 20: 207-216.

Lages-Silva E, Ramirez LE, Krettli AU, Brener Z 1987. Effect of protective and non-protective antibodies in the phagocytosis rate of Trypanosoma cruzi blood forms by mouse peritoneal macrophages. Parasite Immunol 9: 21-30.

Lenzi HL, Oliveira DN, Lima MT, Gattass CR 1996. Trypanosoma cruzi: paninfectivity of CL strain during murine acute infection. Exp Parasitol 84: 16-27.
Ley V, Andrews NW, Robbins ES, Nussenzweig V 1988. Amastigote of Trypanosoma cruzi sustain na infective cycle in mammalian cells. J Exp Med 168: 649659.

Libby P, Alroy J, Pereira MEA 1986. A neuraminidase from Trypanosoma cruzi removes sialic acid from the surface of mammalian myocardial and endothelial cells. J Clin Invest 77: 127-135.

Lima APCA, Tessier DC, Thomas DY, Scharfstein J, Storer AC, Vernet T 1994. Identification of new cysteine protease gene isoforms in Trypanosoma cruzi. Mol Biochem Parasitol 67: 333.

Low HP, Santos MAM, Wizel B, Tarleton RL 1997. Amastigote surface proteins of Trypanosoma cruzi are targets for CD8+ cytotoxic T lymphocytes. $J$ Immunol (in press).

Macedo AM, Pena S 1998. Genetic variability of Trypanosoma cruzi: implications for the pathogenesis of Chagas' disease. Parasitol Today 14: 119-124.

Mariano CR, Dímperio Lima MR, Grisotto MG, Alvarez JM 1999. Influence of acute-phase parasite load pathology, parasitism, and activation of the immune system at the late chronic phase of Chagas' disease. Infect Immun 67: 308-18.

McKerrow JH, McGrath ME, Engel JC 1995. The cysteine protease of Trypanosoma cruzi as a model for antiparasite drug design. Parasitol Today 11: 279282.

Meirelles MN, Juliano L, Carmona E, Silva SG, Costa EM, Murta AC, Scharfstein J 1992. Inhibitors of the major cysteinyl proteinase (GP57/51) impair host cell invasion and arrest the intracellular development of Trypanosoma cruzi in vitro. Mol Biochem Parasitol 52: 175-184.

Melo RC, Brener Z 1978. Tissue tropism of different Trypanosoma cruzi strains. J Parasitol 64: 475-482.

Miles MA, Souza A, Povoa M, Shaw JJ, Lainson R, Toye PJ 1978. Isozymic heterogenity of Trypanosoma cruzi in the first autochtonous patients with Chagas' disease in Amazonian Brazil. Nature 272: 819-821.

Ming M, Ewen ME, Pereira, MEA. 1995. Trypanosoma invasion of mammalian cells requires activation of the TGF $\beta$ signaling pathway. Cell 82: 287-296.

Mombouli JV, Vanhoutte PM 1995. Kinins and endothelial control of vascular smooth muscle. Annu Rev Pharmacol Toxicol 35: 679-705.

Morel C, Chiari E, Camargo EP, Mattei DM, Romanha AJ, Simpson L 1980. Strains and clones of Trypanosoma cruzi can be characterized by restriction endonucleases fingerprint of kinetoplast DNA molecules. Proc Natl Acad Sci USA 77: 6810-6814.

Morrot A, Dudley KS, Higuchi ML, Reis M, Pedrosa R, Scharfstein J 1997. Human T cell response against the major cysteine proteinase (cruzipain) of Trypanosoma cruzi: role of the multifunctional alpha2macroglobulin receptor in antigen presentation by monocytes. Inter Immunol 9: 825-834.

Morris SA, Tanowitz H, Wittner M, Bilezikjan JP 1990. Pathophysiological insights the cardiomyopathy of Chagas' disease. Circulation 82: 1900.

Murta AC, Persechini PM, Padron T de S, de Souza W, 
Guimaraes JA, Scharfstein J 1990. Structural and functional identification of GP57/51 antigen of Trypanosoma cruzi as a cysteine proteinase. $\mathrm{Mol}$ Biochem Parasitol 43: 27-38.

Munoz-Fernandez M, Fernandez MA, Fresno M 1992. Synergism between tumor necrosis factor-alpha and interferon-gama on macrophage activation for the killing of intra cellular Trypanosoma cruzi throught a nitric oxide-dependent mechanism. Eur J Immunol 22: 301-307.

Pereira ME, Zhang K, Gong Y, Herrera EM, Ming M 1996. Invasive phenotype of Trypanosoma cruzi restricted to a population expressing trans-sialidase. Infect Immun 64: 3884-3892.

Postan M, Cheever AW, Dvorak JA, McDaniel JP 1996. A histopathological analysis of the course of myocarditis in $\mathrm{C} 3 \mathrm{H} / \mathrm{He}$ mice infected with Trypanosoma cruzi clone Sylvio-X10/4. Trans $R$ Soc Trop Med Hyg 80: 50-55.

Procopio DO, Teixeira MM, Camargo M, Travassos LR, Ferguson MA, Almeida IC, Gazzinelli RT 1999. Differential inihibitory mechanism of cyclic AMP on TNF a and IL12 synthesis by macrophages exposed to microbial stimuli. British J Pharmacol (in press).

Ready PD, Miles MA 1980. Delimitation of Trypanosoma cruzi zymodemes by numerical taxonomy. Trans $R$ Soc Trop Med Hyg 74: 238-242.

Regoli D 1980. Kinins. Brit Med Bull 43: 270-280.

Reis MM, Higuchi ML, Benvenuti LA, Aiello VD, Gutierrez PS, Bellotti G, Pileggi Fulvio 1997. An in situ quantitative immunohistochemical study of cytokines and IL-2R+ in chronic human chagasic myocarditis: correlation with the presence of myocardial Trypanosome cruzi antigens. Clin Immunol Immunopathol 83: 165-172.

Revolo S, Oury B, Laurent J, Barnabe C, Quesney V, Carriere V, Noel S, Tibayrenc M 1998. Trypanosoma cruzi: impact of clonal evolution of the parasite on its biological and medical properties. Exp Parasitol 89: 30-39.

Ribeiro dos Santos R, Hudson L 1980. Trypanosoma cruzi: binding of parasite antigens to mammalian cell membranes. Clin Exp Immunol 40: 36-41.

Ribeiro dos Santos R, Rossi MA, Sauss JL, Silva JS, Savino W, Mengel J 1992. Anti-CD4 abrogates rejection aand reestablishes long-term tolerance to syngeneic newborn hearts grafted in mice chronically infected with Trypanosoma cruzi. J Exp Med 175: 28-39.

Romanha AJ, Da Silva Pereira AA, Chiari E, Kilgour V 1979. Isoenzyme pattern of cultured Trypanosoma cruzi: changes after prolonged subculture. Comp Biochem Parasitol 62B: 139-142.

Rossi MA 1990. Microvascular changes as a cause of chronic cardiomyopathy in Chagas' disease. Am Heart J 120: 233-236.

Russo M, Starobinas N, Minoprio P, Coutinho A, Hontebeyrie-Joskowicz M 1988. Parasitic load increases and myocardial inflammation decreases in T. cruzi-infected mice after inactivation of helper $\mathrm{T}$ cells. Ann Inst Pasteur/Immunol 139: 225-236.
Salazar NA, Mondragon A, Kelly JM 1996. Mucin-like glycoprotein genes are closely linked to members of the trans-sialidase super-family at multiple sites in the Trypanosoma cruzi genome. Mol Bioch Parasitol 78: 127-136.

Scharfstein J, Abrahamson M, Souza-Palatnik CB, Barral e Silva A, Silva IV 1995. Antigenicity of cystatinbinding proteins from parasitic protozoan: detection by a proteinase-inhibitor based capture immunoassay (PINC-ELISA). J Immunol Methods 182: 63-72.

Scharfstein J, Rodrigues MM, Alves CA, de Souza W, Previato JO, Mendonça-Previato L 1983. Trypanosoma cruzi: description of a highly purified surface antigen defined by human antibodies. J Immunol 131: 972-976.

Scharfstein J, Schechter M, Senna M, Peralta JM, Mendonça-Previato L, Miles MA 1986. Trypanosoma cruzi: characterization and isolation of a 57/ 51000 molecular weight surface glycoprotein (GP-57/51) expressed by epimatigotes and bloodstream trypomatigotes. J Immunol 137: 1336-1341.

Schenckman S, Eichinger D, Pereira MEA, Nussenzweig V 1994. Structural and functional properties of Trypanosoma cruzi trans-sialidase. Annu Rev Microbil 48: 499-523.

Silva JS, Morrissey PJ, Grabstein KH, Mohler KM, Anderson D, Reed SG 1992. Interleukin 10 and IFNgama regulation of experimental Trypanosoma cruzi infection. J Exp Med 175: 169-174.

Stoka V, Nycander M, Lenarcic B, Labriola C, Cazzulo JJ, Bjork I, Turk V 1995. Inhibition of cruzipain, the major cysteine proteinase of the protozoan parasite, Trypanosoma cruzi, by proteinase inhibitors of the cystatin superfamily. FEBS Letters 370: 101-104.

Svensjo E, Cyrino FZ, Juliano L, Scharfstein J 1997. Plasma leakage induced in postcapillary venules by the major cysteine-proteinase from Trypanosoma cruzi and its modulation by H1-blocker mepyramine. Microvasc Res 54: 93-97.

Takle GB, Cross GAM 1991. An 85-kilodalton surface antigen gene family of Trypanosoma cruzi encodes polypeptides homologous to bacterial neuraminidases. Mol Bioch Parasitol 48: 185-198.

Tarleton RL, Koller BH, Latour A, Postan M 1992. Susceptibility of beta 2-microglobulin-deficient mice to Trypanosoma cruzi infection. Nature 26, 356(6367): 338-340.

Teixeira ARL, Teixeira G, Macedo V, Prata A 1978. Acquired cell-mediated rimmunodepression in acute Chagas' disease. J Clin Inv 62: 1132-1141.

Teixeira VDPA, Hial V, Gomes RADS, Castro ECC, Reis MG, Rodrigues MLP, Guimarães JV, Rei MA 1997. Correlation between adrenal central vein parasitism and heart fibrosis in chronic chagasic myocarditis. Amer J Trop Med Hyg 56: 177-180.

Tibayrenc M, Ward P, Moya A, Ayala FJ 1986. Natural population of Trypanosoma cruzi, the agent of Chagas' disease, have a complex multiclonal structure. Proc Natl Acad Sci USA 83: 115-119.

Tomas AM, Kelly JM 1996. Stage-regulated expression of cruzipain, the major cysteine-proteinase of Trypanosoma cruzi is independent of the level of RNA. 
Mol Biochem Parasitol 76: 91-103.

Trischman T, Tanowitz H, Wittner M, Bloom B 1978. Trypanosoma cruzi: role of the immune response in the natural resistance of inbred strains of mice. Exp Parasitol 45: 160-168.

Wizel B, Nunes M, Tarleton RL 1997. Identification of a Trypanosoma cruzi trans-sialidase family member as a target of protective $\mathrm{CD} 8+\mathrm{Tc} 1$ responses. $J$ Immunol 159: 6120-6130.

Wizel B, Palmieri M, Mendoza C, Arana B, Sideney J,
Sette A, Tarleton R 1998. Human infection with Trypanosoma cruzi induces parasite antigen-specific cytotoxic T lymphocyte responses. J Clin Invest 102: 1062-1071.

Zhang L, Tarleton RL 1996. Persistent production of inflammatory and anti- inflammatory cytokines and associated MHC and adhesion molecule expression at the site of infection and disease in experimental Trypanosoma cruzi infections. Exp Parasitol 84: 203-213. 